\title{
The Development of a Control System for a 5 Kilowatt Free Piston Stirling Space Convertor
}

\author{
Raymond L. Kirby ${ }^{1}$, and N. Vitale ${ }^{2}$ \\ ${ }^{1}$ Space Research Institute, 231 Leach Center, Auburn University, Auburn University, AL, USA 36849-5320 \\ 334-844-5911, kirbyrl@auburn.edu \\ ${ }^{2}$ Foster-Miller, Inc., 431 New Karner Rd., Albany, NY, USA 12205
}

\begin{abstract}
The new NASA Vision for Exploration, announced by President Bush in January 2004, proposes an ambitious program that plans to return astronauts to the moon by the 2018 time frame. A recent NASA study entitled "Affordable Fission Surface Power Study" recommended a 40 kWe, 900 K, NaK-cooled, Stirling conversion for 2020 launch. Use of two of the nominal $5 \mathrm{~kW}$ converters allows the system to be dynamically balanced. A group of four dual-converter combinations that would yield $40 \mathrm{kWe}$ can be tested to validate the viability of Stirling technology for space fission surface power systems. The work described in this paper deals specifically with the control system for the $5 \mathrm{~kW}$ convertor described in the preceding paragraph. This control system is responsible for maintaining piston stroke to a setpoint in the presence of various disturbances including electrical load variations. Pulse starting of the FSPE convertor is also an inherent part of such a control system. Finally, the ability to throttle the engine to match the required output power is discussed in terms of setpoint control. Several novel ideas have been incorporated into the piston stroke control strategy that will engender a stable response to disturbances in the presence of midpoint drift while providing useful data regarding the position of both the power piston and displacer.
\end{abstract}

Keywords: Stirling engine, space power

PACS: 84.60.h.

\section{INTRODUCTION}

Kankam et al. (Kankam, 1992; Benvenuto, 1994; Regan, 2004) have investigated the dynamic properties of the Free-Piston Stirling Engine. The FPSE is an inherently unstable system under certain conditions. This means that the piston stroke will grow without bound until the mechanical endpoints are reached under these conditions. Moreover, the FPSE can be stable and oscillatory or stable and damped under different conditions. The objective of the control system is to cause the engine to be stable and oscillatory at its resonant frequency and maximum piston stroke. This combined with proper power factor control will yield maximum alternator output power. The conditions for stability will be discussed later.

The FPSE used in this work will be capable of producing 400 volts RMS at 5 kilowatts with a $22 \mathrm{~mm}$ peak-topeak stroke at a frequency of 85 hertz. The engine will be pulsed started by applying a short AC burst at 85 hertz. Once the engine stroke is sustained the stroke control circuit will maintain the stroke amplitude at the setpoint value. The setpoint range is between 11 and $22 \mathrm{~mm}$ peak to peak.

A master controller will monitor all subordinate controllers including: the stroke controller, the hot oil controller, and the cooling loop. In the event there is a problem with any of these subordinate controllers the master controller will implement a safe shutdown of the entire system. A touch screen will provide the user interface for the control system. Process data will be displayed and operator functions can be performed via the touch screen. For example, the stroke setpoint can be changed via the touch screen.

The objective of this work was to understand the dynamic characteristics of a free piston Stirling engine and to establish an acceptable method of controlling the piston stroke of the engine. In order to experiment with various control strategies, without damage to the actual engine, a dynamic model of the engine was developed. 
The model was then used to analyze different control strategies. Once a control strategy was selected the implementation of the control strategy is discussed. The linear dynamical model is shown in Figure 1.

\section{THE FPSE DYNAMIC MODEL}

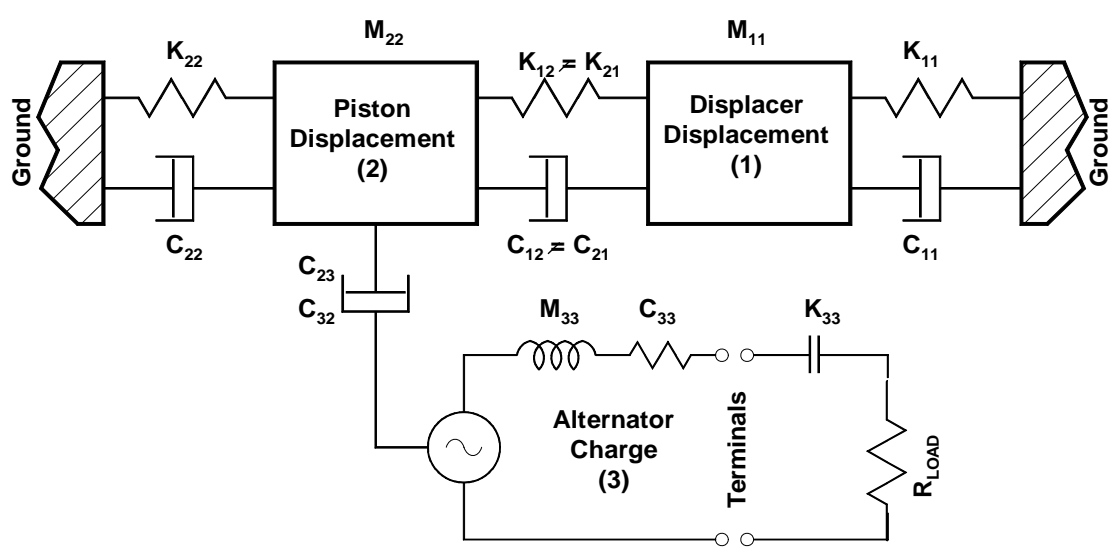

FIGURE 1. Elements of the Auburn Free -Piston Linear Dynamical Model.

The engine-alternator is mounted on a heavy steel plate that is sized so that the vibration amplitude of the engine casing is approximately 1 mil $(25 \mu)$. For all practical purposes, the engine casing can be considered as ground as shown in figure 1.

The relative spring and damping parameters: $\mathrm{K}_{12}, \mathrm{~K}_{21}, \mathrm{C}_{12}$, and $\mathrm{C}_{21}$ represent the engine thermodynamics and are determined from the HFAST2 thermodynamics code. Due to the temperature difference between the expansion and compression spaces the two spring coefficients and the two damping coefficients are not equal to each other as would normally be the case in a passive dynamical system. The difference between the spring coefficients is what gives the dynamical system the ability to generate power. The hot end temperature is maintained at $830^{\circ} \mathrm{K}$ while the cold end is $415^{\circ} \mathrm{K}$.

The spring and damping coefficients to ground $\mathrm{K}_{11}, \mathrm{~K}_{22}, \mathrm{C}_{11}$, and $\mathrm{C}_{22}$ are determined from the STIRDYN dynamics code to achieve operation of the engine at the proper frequency $(85 \mathrm{~Hz})$ and displacer phase angle $\left(70^{\circ}\right)$.

The damping coefficient connecting the piston to the alternator circuit, $\mathrm{C}_{32}$, has the units Volt-second $/ \mathrm{meter}(\mathrm{E}-\mathrm{s} / \mathrm{m}$, where $\mathrm{E}$ is the alternator generated voltage) and the corresponding coefficient connecting the alternator circuit to the piston, $\mathrm{C}_{23}$, has the units newton / ampere (F/A). Conservation of energy requires that the mechanical power delivered to the alternator by the piston $\left(\mathrm{F}^{*} \mathrm{~V}\right)$ equals the mechanical power absorbed by the alternator $\left(\mathrm{E}^{*} \mathrm{i}\right)$, i.e.

$$
-F \cdot v=E \cdot i, \text { or, }-\frac{F}{i}=\frac{E}{v} .
$$

\section{Model Equations:}

The differential equations describing the dynamics are given in equation (2).

$$
\begin{aligned}
& m_{11} \ddot{x_{d}}+c_{11} \dot{x_{d}}+c_{12} \dot{x_{p}}+k_{11} x_{d}+k_{12} x_{p}=0, \\
& m_{22} \ddot{x_{p}}+c_{21} \dot{x_{d}}+c_{22} \dot{x_{p}}+c_{23} \dot{q}+k_{21} x_{d}+k_{22} x_{p}=0, \\
& m_{33} \ddot{q}+c_{32} \dot{x}_{p}+c_{33} \dot{q}+k_{33} q=v .
\end{aligned}
$$


If the temperature ratio of the engine was 1.0 , then the $\mathrm{k} 12$ would be negative and equal to $\mathrm{k} 21$. If the displacer rod area were zero and the temperature ratio of the engine was 0 , then both spring terms would be zero. The load resistance is estimated to be $31.053 \Omega$. Equation set (2) was used to develop a state space model (SSM) of the engine dynamics. The form of the SSM is given in equation (3).

$$
\dot{[x}]=[A] x+[B] u \text { and }[y]=[C] x
$$

$\mathrm{A}, \mathrm{B}$ and $\mathrm{C}$ are given as:

$$
\begin{aligned}
& A=\left[\begin{array}{cccccc}
0 & 1 & 0 & 0 & 0 & 0 \\
-k_{33} / m_{33} & -c_{33} / m_{33} & 0 & -c_{32} / m_{33} & 0 & 0 \\
0 & 0 & 0 & 1 & 0 & 0 \\
0 & -c_{23} / m_{22} & -k_{22} / m_{22} & -c_{22} / m_{22} & -k_{21} / m_{22} & -c_{21} / m_{22} \\
0 & 0 & 0 & 0 & 0 & 1 \\
0 & 0 & -k_{12} / m_{11} & -c_{12} / m_{11} & -k_{11} / m_{11} & -c_{11} / m_{11}
\end{array}\right], \\
& A=\left[\begin{array}{cccccc}
0 & 1 & 0 & 0 & 0 & 0 \\
-2.8524 & -.0006 & 0 & -.0154 & 0 & 0 \\
0 & 0 & 0 & 1 & 0 & 0 \\
0 & .0002 & -2.9787 & -.0002 & .4944 & .0001 \\
0 & 0 & 0 & 0 & 0 & 1 \\
0 & 0 & -.1563 & .0004 & -3.0113 & -.0005
\end{array}\right] \times 10^{5}, \\
& B=\left[\begin{array}{c}
0 \\
1 / m_{33} \\
0 \\
0 \\
0 \\
0
\end{array}\right]=\left[\begin{array}{c}
0 \\
14.042 \\
0 \\
0 \\
0 \\
0
\end{array}\right] \\
& C=\left[\begin{array}{llllll}
0 & 0 & 1 & 0 & 0 & 0
\end{array}\right] .
\end{aligned}
$$

The state variables were selected as follows: $\mathrm{x}_{1}=\mathrm{q}$ (charge), $\mathrm{x}_{2}=\dot{q}$ (current), $\mathrm{x}_{3}=\mathrm{x}_{\mathrm{p}}$ (piston displacement), $\mathrm{x}_{4}=$ $\dot{x}_{p}$ (piston velocity), $\mathrm{x}_{5}=\mathrm{x}_{\mathrm{d}}$ (displacer displacement), $\mathrm{x}_{6}=\dot{x}_{d}$ (displacer velocity). Note that the output voltage is a function of piston velocity and that $c_{33}$ is the total resistance in series with the alternator. This includes the armature resistance and the load resistance. Also, $\dot{c}_{33}$ is the armature resistance. 


\section{THE OPEN LOOP CHARACTERISTICS}

As mentioned earlier there are three possible modes; stable and oscillatory, unstable and oscillatory, and stable but damped. With all other coefficients constant, $c_{33}$ determines in which mode the dynamic system with be. If $c_{33}=$ $35.489 \mathrm{ohms}$ the system is stable and oscillatory. The eigenvalues (open loop poles) are located in the complex frequency plane as follows: $-210.69 \pm \mathrm{j} 486.34,-70 \pm \mathrm{j} 563.12,0 \pm \mathrm{j} 534.07$. The root locus is shown in Figure 2 .

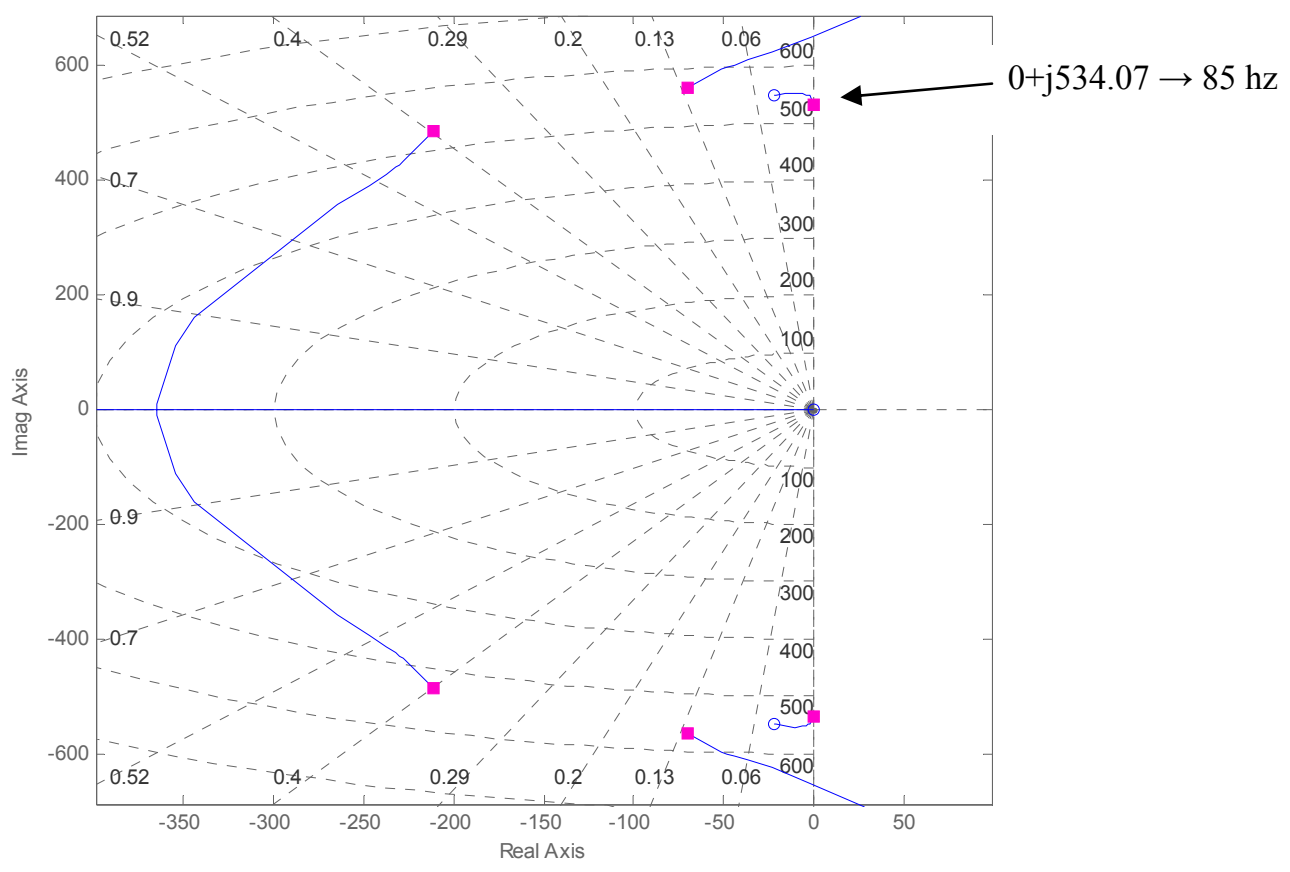

FIGURE 2. Root Locus with $\mathrm{c}_{33}=35.489$.

The response to a 22 volt AC burst applied to the input terminals for 2 seconds is shown in Figure 3 .

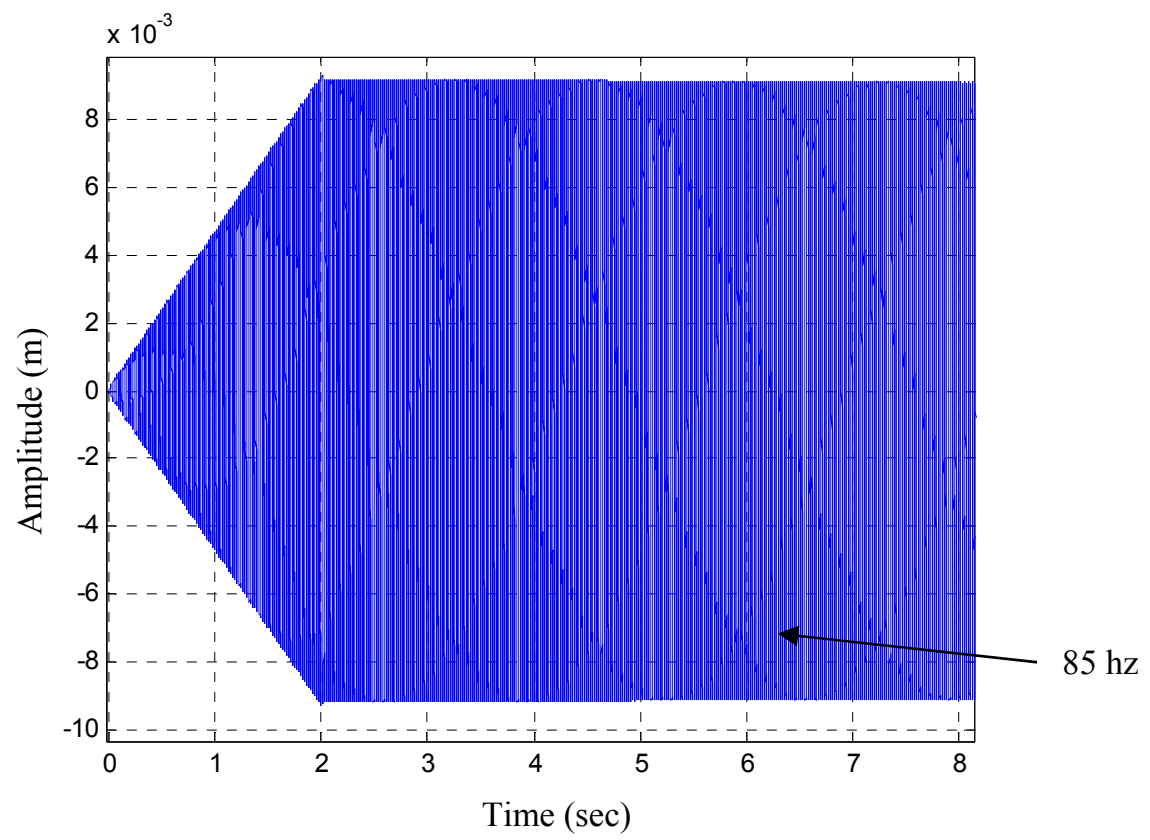

FIGURE 3. Burst Response with $c_{33}=35.489$. 
If $c_{33}$ is changed to $40 \mathrm{ohms}$ the system is unstable and the open loop poles are as follows: $-248.20 \pm \mathrm{j} 469.95$, $65.89 \pm 562.3,1.41 \pm 533.89$. The root locus is shown in Figure 4. Notice that one complex conjugate pair of poles $(1.41 \pm \mathrm{j} 533.89)$ are now in the right half plane and the response will be unstable. The resistance change from 35.489 to $40 \mathrm{ohms}$ has resulted in an $18 \%$ change in the real part of the largest pair and a $7 \%$ change in the real part of the other pair in the left half plane. This shows the sensitivity of these poles to

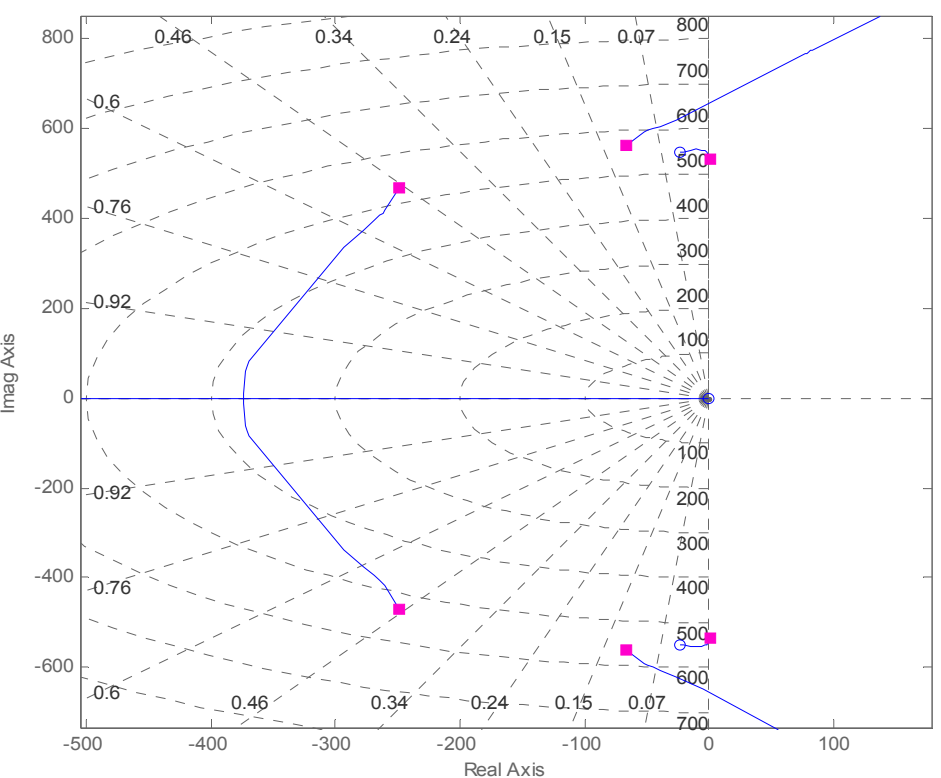

FIGURE 4. Root Locus with $c_{33}=40$ ohms. changes in resistance.

The poles closest to the imaginary axis will dominate the response as poles with large real parts result in a faster response and their affect on total response may small compared to those close to the imaginary axis. Notice that there is a pair of complex conjugate poles in the right half plane (RHP) which is unstable. The response to a 22 volt $\mathrm{AC}$ signal applied to the input terminals for 2 seconds is shown in Figure 5.

Finally, suppose $c_{33}$ is changed to 30 ohms. The open loop poles are as follows:- $160 \pm j 449.9, \quad-80 \pm j 566.88$, 21.6 $\pm \mathrm{j} 534.46$. This system will be stable and damped as shown in Figure 6 . The response to a 22 volt AC signal applied to the input terminals for 2

seconds is shown in Figure 7. Comparing the root locus for each case one can begin to understand the sensitivity of the open loop poles to changes in resistance. With a resistance greater than 35.489 ohms the system becomes unstable. If the resistance is less than $35.489 \mathrm{ohms}$ the system is damped and the response is dominated by the complex conjugate pair of poles closest to the origin. The controller will have to force the resistance to 35.489 ohms in the presence of user load changes. The controller should react to an increase in resistance so as to prevent over stroking the engine. Over stroking can result in permanent damage to the engine.

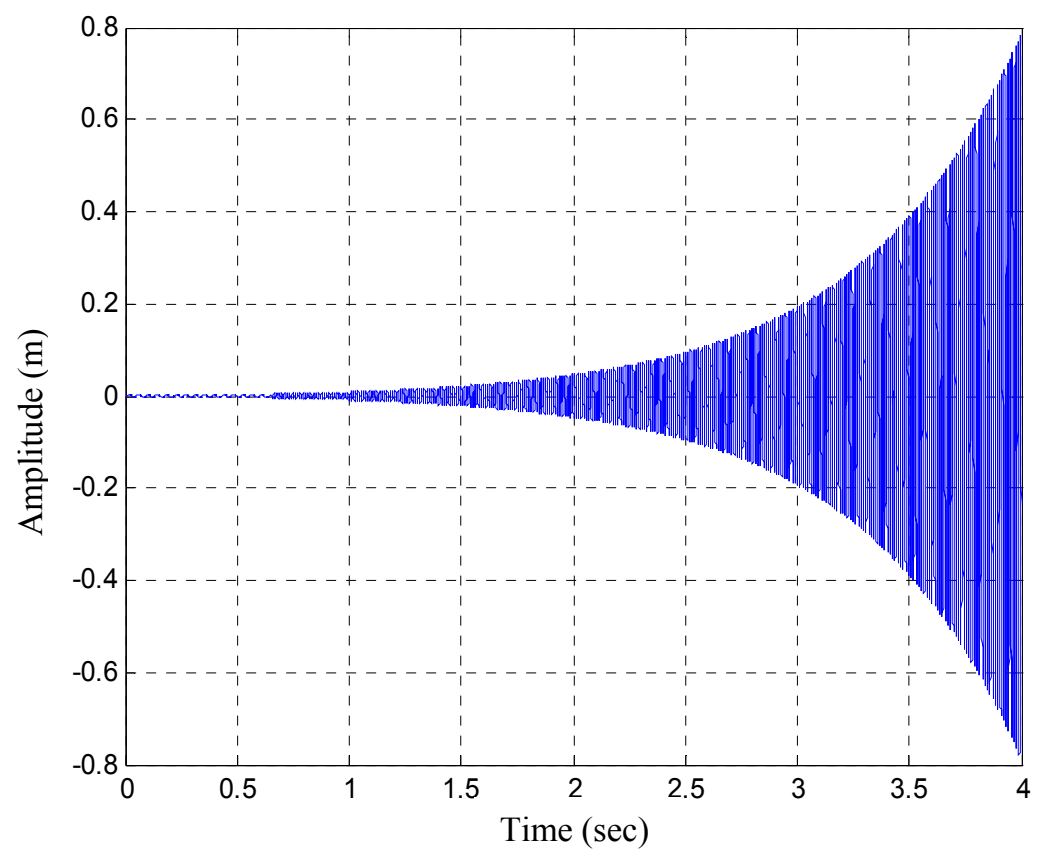

FIGURE 5. Burst Response with $\mathrm{c}_{33}=40 \mathrm{ohms}$. 


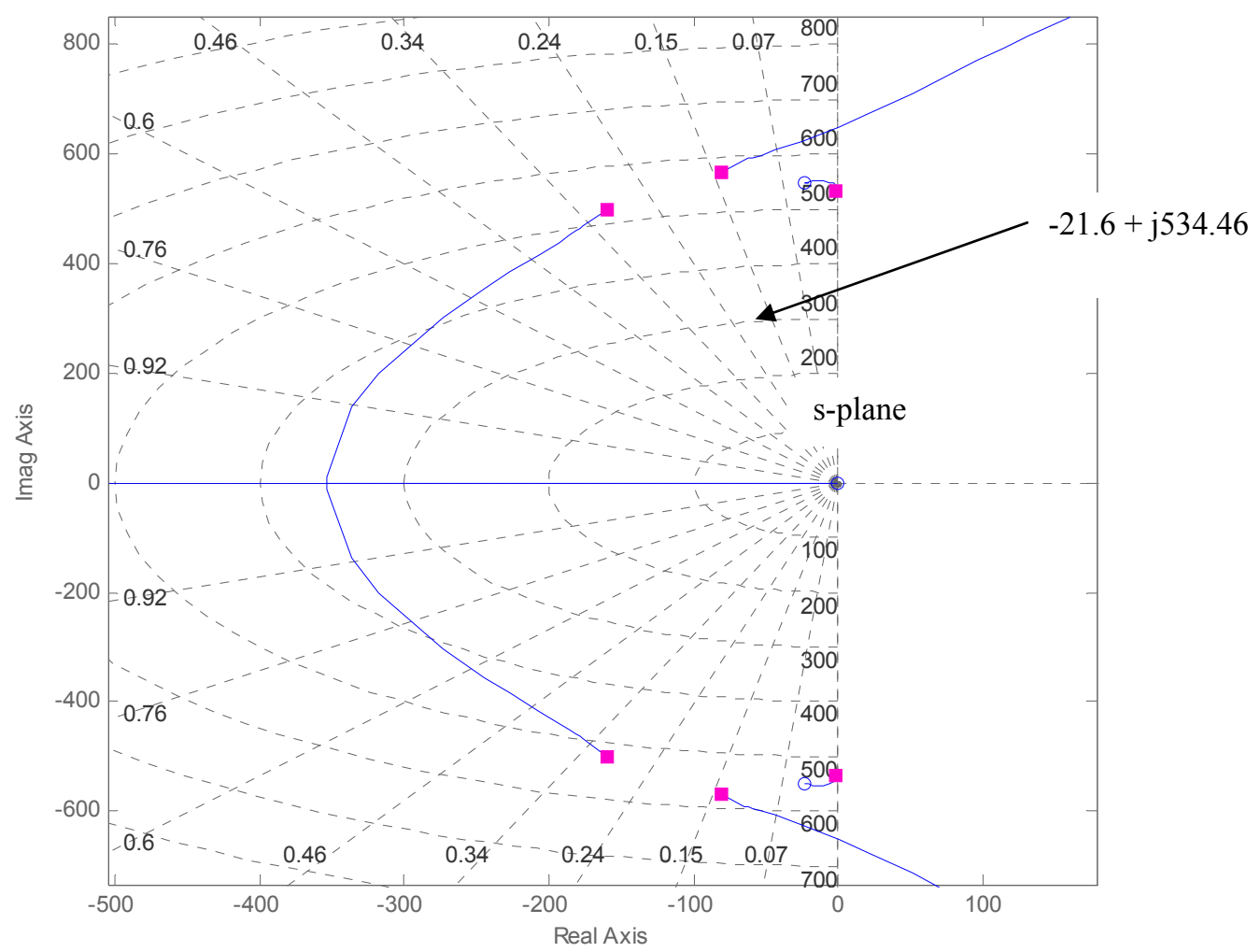

FIGURE 6. Root Locus with $c_{33}=30$ ohms.

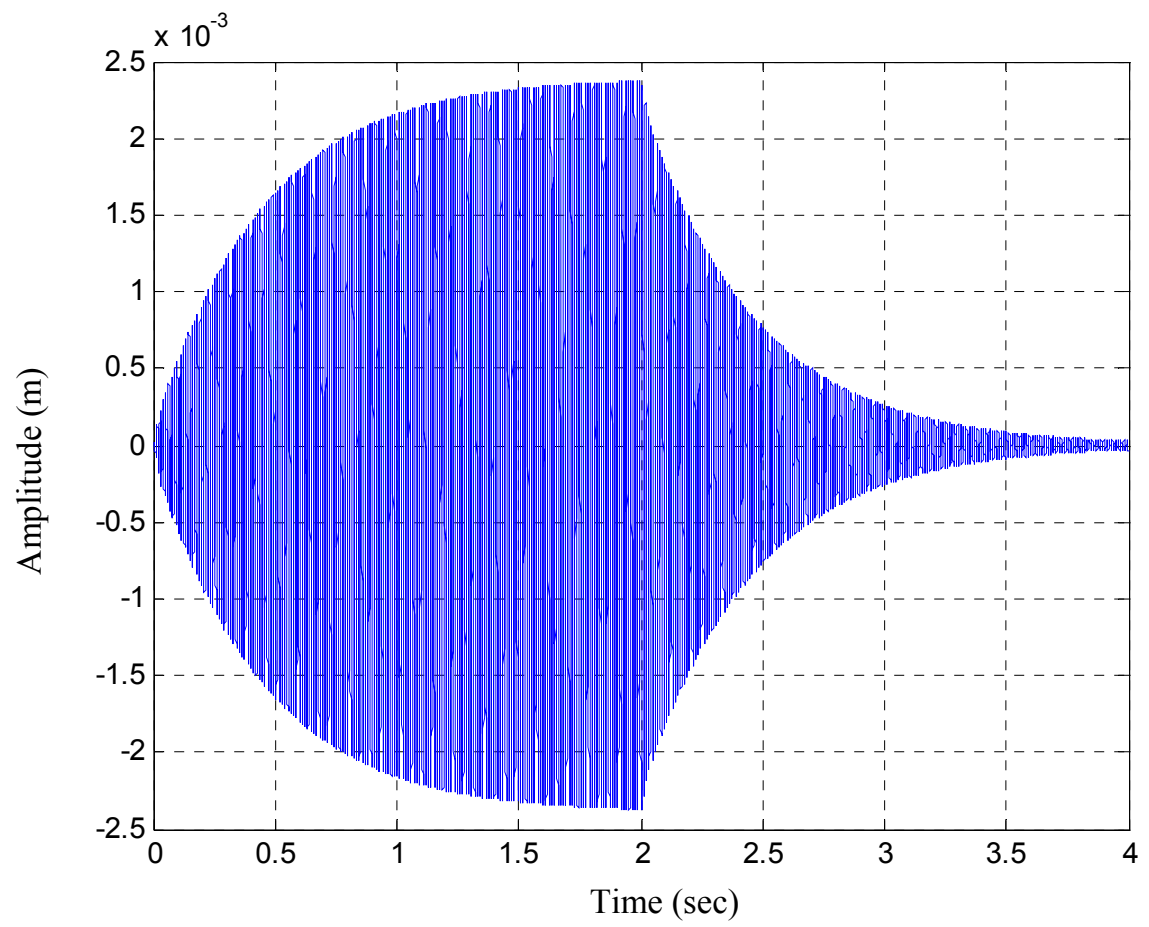

FIGURE 7. Burst Response with $c_{33}=30$ ohms. 


\section{THE CONTROL STRATEGY}

One method of preventing the engine from over stroking and endure oscillation is to maintain a pair of complex conjugate closed loop poles on the imaginary axis in the s-plane as is the case in the open loop with $\mathrm{c}_{33}=35.849$ ohms. Remember, stability is also a function of the hot end and cold end temperatures and therefore can become unstable in the open loop with 35.849 ohms. Clearly, a closed loop control is required that can maintain stability over a range of stroke setpoints.

A displacement transducer is used to measure the piston stroke and serve as the feedback, or process variable, in a closed loop control scheme. The output of the controller can affect a change in total resistance via a proportional pulse width modulation (PWM) switching of the control load. This will keep the stroke at the setpoint value.

The setpoint controller is an algorithm which will adjust the stroke setpoint to match the user load requirements. Therefore, a non-dissipative type control scheme is realized which essentially throttles the FPSE. A block diagram of the control scheme is shown in Figure 8. Control load current, user load current, and terminal voltage serve as inputs to the setpoint control algorithm. The output of the setpoint control algorithm is the stroke setpoint.

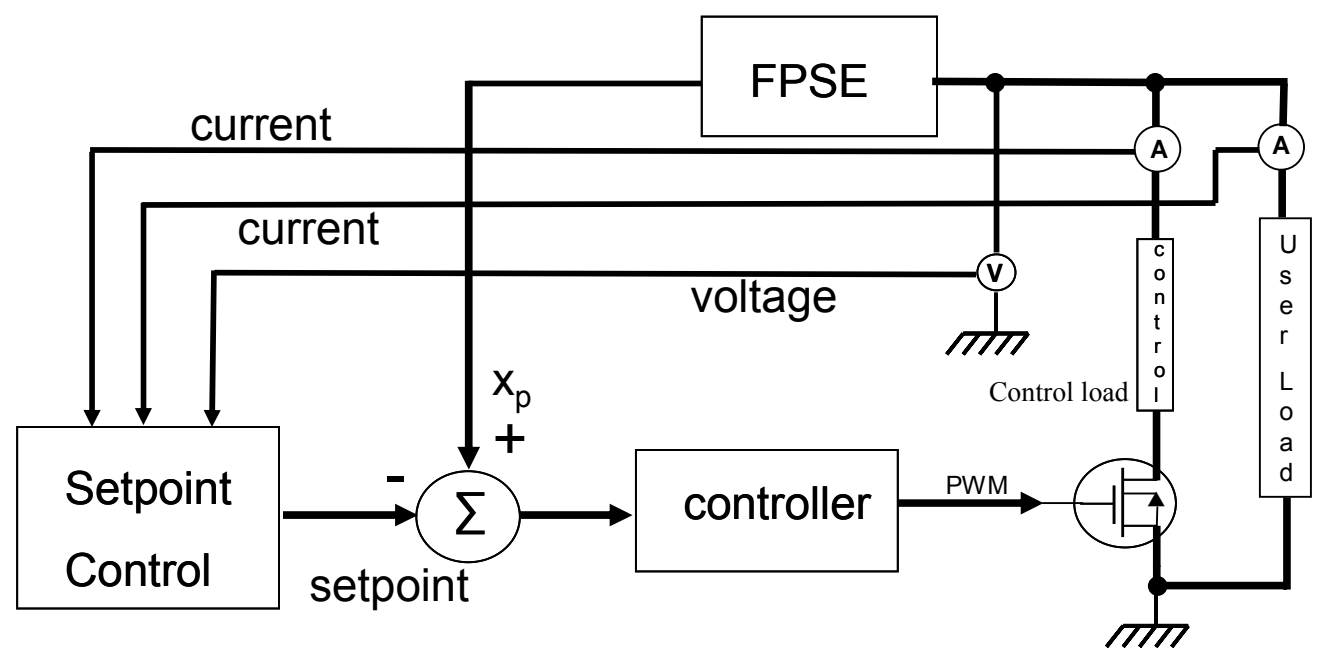

FIGURE 8. Control System Block Diagram.

To prevent steady state error in the stroke amplitude integral action is incorporated into the control law. This places a zero and a pole in the loop transmission. The pole is located at the origin, $0+\mathrm{j} 0$, while the zero is located in the left half plane to provide an acceptable disturbance response. Locating the zero is a part of the controller tuning procedure.

The stroke setpoint is manipulated based on the user load demand. That is, as the user load is increased, load resistance is lowered, and the stroke setpoint is increased. As the user load is decreased the stroke setpoint is decreased. The result is a non-dissipative control which throttles the FSPE to match the user load. The control load current is minimized to conserve fuel.

\section{CONTROLLER TUNING}

A proportional-Integral (PI) control law was used as the controller. The PI control law transfer function is given by equation (5).

$$
\frac{U(s)}{E(s)}=\frac{K_{p}\left(s+1 / \tau_{I}\right)}{s}=\frac{8.625(s+10)}{s}
$$


The closed loop poles are shown are: $0 \pm \mathrm{j} 534.08,-70.408 \pm \mathrm{j} 563.14,-210 \pm \mathrm{j} 486.3$. As the user load resistance changes the open loop poles change value. The controller alters the total resistance to force the closed loop poles to the values listed above. Notice that the controller zero is located at $\mathrm{s}=-10$. This results in a small integral gain as the

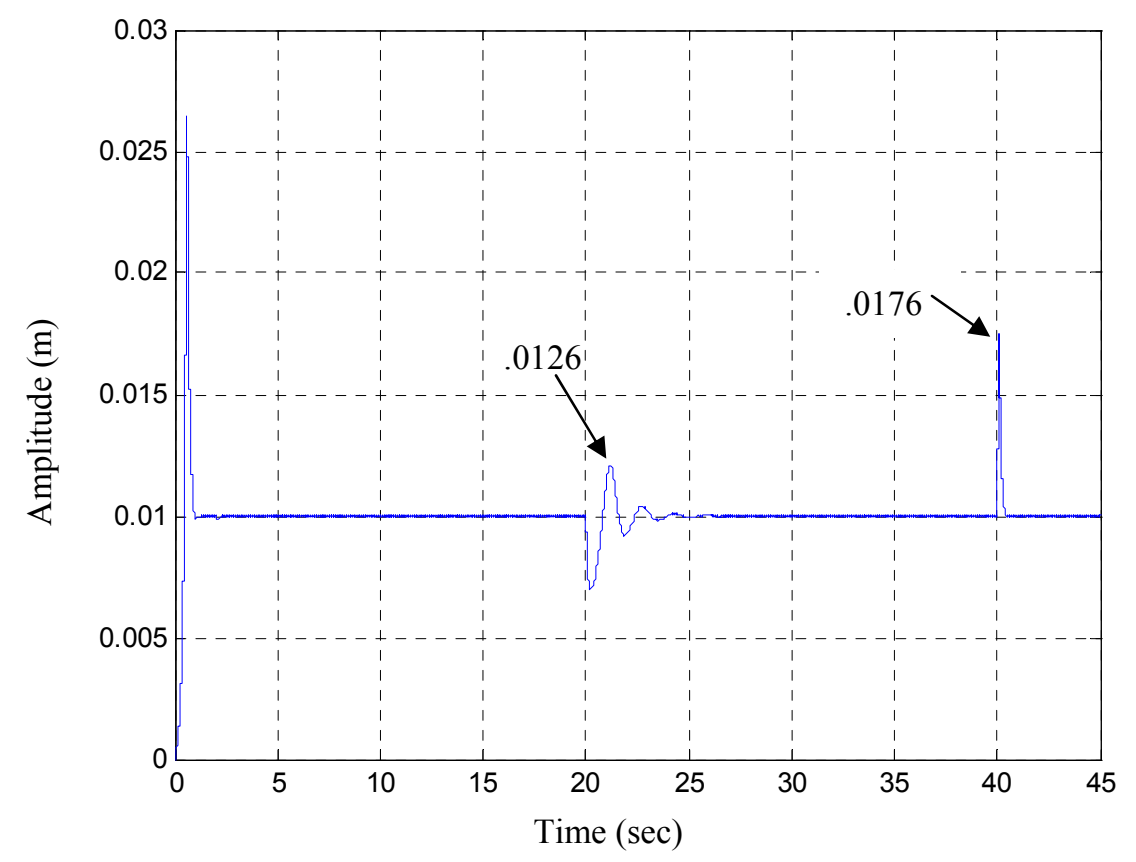
zero is much closer to the origin than the open loop poles. If the controller zero is too large (high integral gain) the overshoot from a load change would be excessive and allow the engine to over stroke. With the piston amplitude setpoint at 0.010 . meters the response to a 2 second burst is shown in Figure 9. After 20 seconds the load resistance was changed from 1000 ohms to 40 ohms. Then at 40 seconds the load resistor was changed back to $1000 \mathrm{ohms}$.

It should be pointed out that over stroking occurs when the amplitude exceeds .012 meters. In order to minimize the overshoot during a pulse start or from a load disturbance a phase lead network is incorporated into the control law. The lead network has the following transfer function:

$$
\frac{Y(s)}{U(s)}=\frac{K_{L}(s+a)}{s+b}=\frac{10(s+.01)}{s+.1}, \text { Where } \mathrm{a}<\mathrm{b}
$$

Figure 10 shows the improved response when the lead network is included. Note that the overshoot has been reduced but has not been eliminated. Further work is being done to further reduce the overshoot.

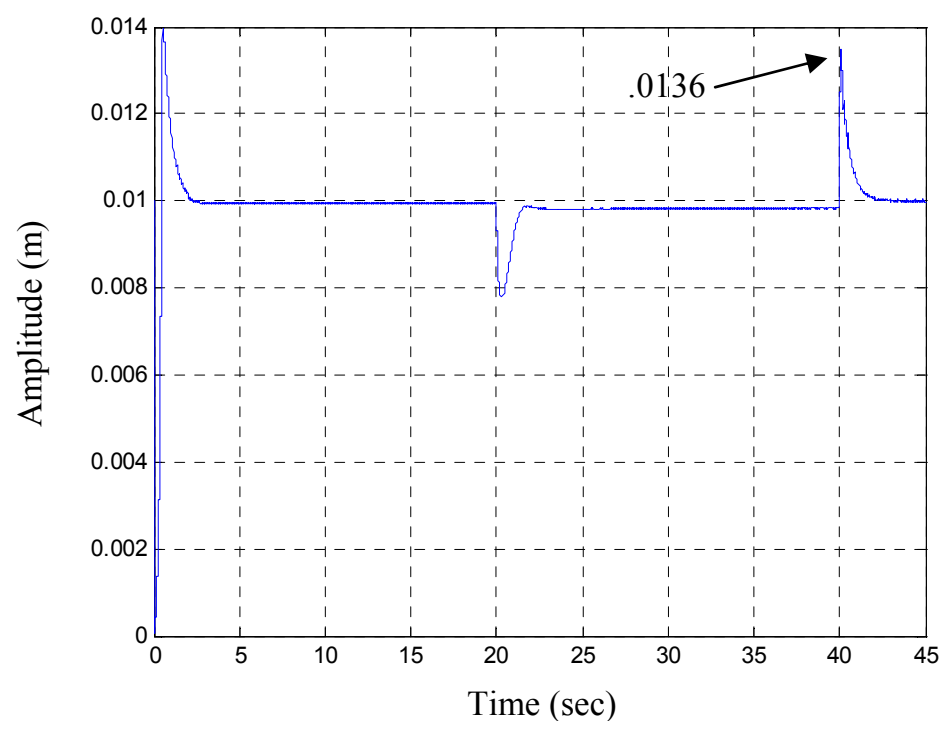

FIGURE 10. System Response to Load Disturbance with PID + Lead. 
Consider the third equation in Equation (2).

$$
m_{33} \ddot{q}+c_{32} \dot{x_{p}}+c_{33} \dot{q}+k_{33} q=v
$$

Let $\mathrm{v}=0$ and realize that

$$
c_{33}=c_{33}^{\prime}+\frac{R_{C} R_{L}}{R_{C}+R_{L}}
$$

Taking the Laplace transform of Equation 3 we get:

$$
\begin{gathered}
m_{33} s^{2} Q(s)+c_{32} s X_{p}(s)+c_{33} s Q(s)+k_{33} Q(s)=0 \\
Q(s)\left[s^{2}+\frac{c^{\prime} 33+\frac{R_{C} R_{L}}{R_{C}+R_{L}}}{m_{33}} s+\frac{k_{33}}{m_{33}}\right]=\frac{-c_{32}}{m_{33}} s X_{p}(s)
\end{gathered}
$$

Since this is an interacting multivariable system changing the total resistance affects all three complex conjugate pairs of closed loop poles. The set furthest from the origin are the most sensitive to changes in resistance as shown earlier. Unfortunately, the set of poles closest to the origin are the least sensitive the changes in resistance. And it is this set of poles that dominate the disturbance response. Notice that one complex conjugate pair of open loop poles is influenced by the roots of equation (5) below.

$$
s^{2}+\frac{c_{33}^{\prime}+\frac{R_{C} R_{L}}{R_{C}+R_{L}}}{m_{33}} s+\frac{k_{33}}{m_{33}}=0
$$

The controller forces $\left(c_{33}^{\prime}+R_{C} R_{L} /\left(R_{C}+R_{L}\right)\right) / m_{33}$ to be equal to 35.489 , in the steady state, by changing $\mathrm{R}_{\mathrm{C}}$ in response to changes in $R_{L}$. This is true regardless of the stroke setpoint.

\section{CONCLUSION}

It is possible to maintain stable operation of a FPSE by forcing the total resistance to the value which locates a pair of complex conjugate pair of system poles on the imaginary axis in the s-plane. As the user load resistance increases the poles tend to move towards the right half plane resulting in instability. Conversely, as the load resistance decreases these poles tend to move away from the imaginary axis and into the left half plane resulting in exponential damping. Therefore, the idea is to keep a pair of complex conjugate poles on the imaginary axis.

Once the system has been stabilized, the stroke setpoint can be changed to match the output power requirements. This, of course, depends on the type of load. If a fixed DC voltage must be maintained for any user load then it may not be feasible to allow the DC voltage to be reduced via the strike setpoint.

The work presented in this paper was based on a linear model of the FPSE that is currently being designed and built by Foster Miller, Inc. Once the engine is built the model and these results will be compared to the system. There are certainly a number of opportunities for nonlinearities to produce results that may differ form those obtained with this model. Hopefully, we can identify and characterize most of these and subsequently incorporate them into the model.

Provided that the real system's dynamic response can be predicted by this model the response to step changes in load, as shown in figure 10, provides an opportunity for further work. This is especially evident when the load is decreased, and the resistance increased, in a step fashion. 


\section{NOMENCLATURE}

$\mathrm{X}_{\mathrm{d}}=$ displacer displacement $(\mathrm{m})$

$\mathrm{x}_{\mathrm{p}}=$ piston displacement $(\mathrm{m})$

$\mathrm{q}=$ charge (coulomb)

$\mathrm{v}=$ voltage applied to alternator terminals (volts)

$\mathrm{v}=$ voltage applied to alternator terminals (volts)

$\mathrm{m}_{\mathrm{xx}}=$ mass coefficients $(\mathrm{kg}), \mathrm{m}_{33}$ is inductance.

$\mathrm{c}_{\mathrm{xx}}=$ damping coefficients

$\mathrm{x}=$ state variables

$\mathrm{K}_{\mathrm{p}}=$ proportional gain

$\mathrm{k}_{\mathrm{xx}}=$ spring coefficients

$\mathrm{u}=$ inputs

$\mathrm{T}_{\mathrm{I}}=$ integral time ( $\mathrm{sec}$ )

$\mathrm{R}_{\mathrm{C}}=$ controller output

$\mathrm{R}_{\mathrm{L}}=$ user load resistance

\section{ACKNOWLEDGMENTS}

This work is supported by NASA through the Exploration Systems Mission Directorate for the Prometheus Program for the Fission Surface Power Project under NASA contract \#NNC06CB81C "Development of High Efficiency, Free-Piston Stirling Converters." Any opinions expressed are those of the authors and do not reflect the views of NASA.

\section{REFERENCES}

Regan, T.F., Gerber, S.S. and Roth, M.E., “Development of a Dynamic, End-to-End Free Piston Stirling Converter Model”, in proceedings of the $37^{\text {th }}$ Intersociety Energy Conversion Engineering Conference (IECEC 2002), 2002

Regan, T.F., Lewandowski, E.J., "Application of GRC Stirling Converter System Dynamic Model.”, in the proceedings of the Second International Energy Conversion Engineering Conference (IECEC 2004) , AIAA, 2004.

Benvenuto, G. and de Monte, F., "Electrodynamic Analysis of Free-Piston Stirling Engine/Linear Alternator Systems", August, 1994, published by the American Institute of Aeronautics and Astronautics, Washington, D.C., AIAA-94-4031-CP

Kankam, M.D., Rauch, J, and Santiago, W., ”Dynamic Analysis pf Free-Piston Stirling Engine/Linear Alternator-Load SystemExperimentally Validated", National Aeronautics and Space Administration Report, NASA-TM-106034, 1992 